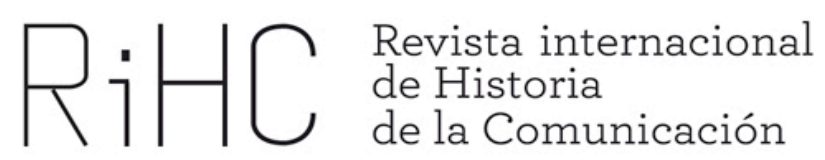

\title{
PRENSA ÉTNICA E INMIGRACIÓN. EL PERIODISMO ESPAÑOL EN MÉXICO EN EL PRIMER TERCIO DEL SIGLO XX
}

DOI: http://dx.doi.org/10.12795/RiHC.2017.i09.02

\author{
Alicia Gil Lázaro ${ }^{1}$ \\ Universidad de Sevilla \\ agil3@us.es
}

Recibido: 11-11-2017

Aceptado: 5-12-2017

Resumen: Este trabajo aborda la acción cultural e intelectual de las comunidades migratorias españolas establecidas en el continente americano en el primer tercio del siglo XX desde la atalaya del periodismo. El problema se examina, en concreto, a partir de un estudio de caso, el del periodismo español en México entre las décadas de 1900 y 1930. Se plantean para ello primeramente las razones de la aparición y crecimiento de un periodismo étnico español durante la gran oleada migratoria hacia América Latina $y$, tras este marco general, el texto se centra en las características propias que adoptó la prensa española en México. En esta parte se ofrece primero un breve panorama de la inmigración en dicho país y después una periodización cuyo fin es mostrar la importancia del contexto político y social del país de acogida a la hora de mantener una producción periodística propia bajo la influencia del ideario hispanoamericanista. El objetivo último es el análisis de la opinión española ante cuestiones candentes de la política mexicana que moldearon la vida diaria de los inmigrantes.

\footnotetext{
${ }^{1}$ Este texto se ha realizado dentro del equipo de investigación HAR2015-64494-R titulado: "La prensa de la emigración española: acción cultural, patriotismo y recreación identitaria. Estudios de caso en Argentina, Cuba, México y Uruguay, 1870-1960”. Agradezco los comentarios de los dos evaluadores anónimos y también las aportaciones de mi equipo.
} 


\title{
Palabras claves:
}

Inmigración española, periodismo étnico, hispanoamericanismo México, revolución.

\begin{abstract}
:
This article deals with the cultural and intellectual action of the Spanish migratory communities settled down in the American countries during the first third of Twentieth Century from the watchtower of journalism. I examine this question, specifically, by a study case, the Spanish journalism in Mexico between 1900 and 1930. First, I set out the reasons of the appraisal and development of an ethnic Spanish journalism during the Great Migration to America, and, after this general framework, I focus in the specific features of the Spanish press in Mexico. In that sense, I show a brief overview of the Spanish community in México, and then, I present a chronological evolution of the Spanish journalism in order to demonstrate the importance of political context of the host country to maintain an own journalist production under the influence of the Hispanic-Americanist ideology. The main objective is to analyse the Spanish public opinion in Mexico about the trending topics of its politics changes, which affected the everyday life of immigrants.
\end{abstract}

Keywords:

Spanish immigration, ethnic journalism, Hispanoamericanism, Mexico, revolution.

\section{Introducción}

Este trabajo aborda la acción cultural e intelectual de las comunidades migratorias españolas establecidas en el continente americano en el primer tercio del siglo XX y desde la atalaya del periodismo. El problema se examina, en concreto, a partir de un estudio de caso, el del periodismo español en México entre las décadas de 1900 y 1930. Se plantean para ello, primeramente, las razones de la aparición y crecimiento de un periodismo étnico español durante la gran oleada migratoria hacia América Latina y, tras este marco general, el texto se centra en las características propias que adoptó la prensa española en México. Ofrecemos primero un breve panorama de la inmigración en dicho país y después una periodización cuyo fin es mostrar la importancia del contexto político y social del país de acogida a la hora de mantener una producción periodística propia bajo la influencia del ideario hispano americanista. El objetivo último es el análisis de la opinión española ante cuestiones candentes de la política mexicana que moldearon la vida diaria de los inmigrantes.

He utilizado para ello una bibliografía alimentada esencialmente por folletos, libros, conferencias, relatos literarios y artículos de prensa, donde los escritores y periodistas radicados en México - como voceros del grupo- volcaron las principales preocupaciones que aquejaron en aquel período a las comunidades inmigradas, su 
visión de España y de sí mismos, de su papel como canalizadores de la identidad hispana y el mensaje hispanoamericanista que sus obras contenían. Acompaña a este esfuerzo de interpretación una bibliografía complementaria sustentada en los principales autores de referencia sobre el hispanoamericanismo y la emigración.

\section{Etnicidad e identidad. La prensa de la inmigración española en América}

Entre los tópicos sobre la emigración comunes a principios del siglo $\mathrm{XX}$, tanto en España como en las Repúblicas americanas, circularon varias ideas en torno a la utilidad del fenómeno migratorio. A pesar de la postura pesimista arraigada secularmente en España que concentraba en la emigración todos los males de la patria, otras voces terminaron decantándose por una versión que defendía las consecuencias positivas que la emigración española a América podía tener en términos no solo económicos - las remesas - sino sobre todo sociales y culturales, pues con su presencia ayudaban a mantener la identidad hispana en el continente. Este planteamiento se encuadró dentro de los postulados generales del hispanoamericanismo y también fue común en muchos autores americanos preocupados por el avance de la influencia cultural estadounidense (Sepúlveda, 2005: 375). Uno de los canales por los que esta corriente floreció en las comunidades migratorias fue la prensa étnica.

La práctica periodística de la emigración española a América desde el último tercio del siglo XIX guarda una estrecha relación con la búsqueda de una recreación identitaria de las comunidades étnicas y también con el lugar que estas buscaban ocupar tanto en la sociedad de recepción como en la de origen. Identidad, reconocimiento y patriotismo constituyeron las ideas claves para entender la acción cultural de los inmigrantes y, dentro de esta acción, destacó especialmente el papel de la prensa y otros medios de comunicación escrita. En efecto, la actividad de los intelectuales, escritores y periodistas españoles en el campo cultural y en la opinión pública latinoamericanas fue importante tanto en la consolidación interna de las colectividades migratorias como para su inserción en los lugares de destino. Por supuesto, las intervenciones de estos agentes culturales deben entenderse como las respuestas a la demanda de una inmigración que, como la española, tenía condiciones de incorporación particulares y a menudo contradictorias, en relación con otras comunidades migratorias europeas en América.

¿Cuáles eran estas condiciones? En primer lugar, en el caso español convergían ciertos factores favorables frente a otras nacionalidades, como la lengua común y la 
proximidad cultural. Sin embargo, la historia política compartida ejercía de contrapeso negativo por los siglos coloniales, revoluciones y guerras de independencia y su huella posterior bajo la forma de una extendida hispanofobia característica de las primeras etapas en la construcción de los estados nacionales latinoamericanos (Moya, 2004: 349-402; Pérez Vejo, 2010: 219-230). En el caso de México esto se hizo especialmente relevante durante la década revolucionaria (Yankelevich, 2004). ${ }^{2}$

En segundo lugar, los gobiernos liberales americanos, al tiempo que fomentaron políticas públicas de atracción de inmigrantes europeos, también buscaron activamente su arraigo pleno en el territorio a través de estrategias integradoras con las que pretendían crear identidades nuevas que sustituyeran de forma gradual a las de origen (Devoto, 2004: 173-217).

En tercer lugar, el deterioro de las condiciones de vida que impulsó a millones de españoles a emigrar, la heterogeneidad étnica de este contingente migratorio y el poco interés que en general mostraba el Estado español por sus emigrantes una vez que se iban y se establecían en el exterior, no hicieron sino aumentar la vulnerabilidad de estos frente a las políticas de asimilación de los Estados de acogida (Fernández, 2009: 265-295). Todo ello llevó a las élites económicas e intelectuales de las colectividades españolas en los países latinoamericanos a liderar proyectos de inserción que supusieran una resistencia a ese asimilacionismo estatal latinoamericano.

¿Cómo lo hicieron? Según Marcela García Sebastiani, al papel usual de las élites migratorias como agentes de control social sobre el colectivo étnico, se unía otro más importante, si cabe, como codificadoras de identidades y catalizadoras de los símbolos y expresiones del patriotismo. Actuaban, en este sentido, como puentes de mediación entre el mundo de la inmigración y los contextos receptores (2005: 148). Así, los personajes encumbrados económica y socialmente dentro de las colectividades trataron en general de convertirse en interlocutores fiables de las élites locales y

\footnotetext{
${ }^{2}$ La revolución mexicana, según P. Yankelevich, desarrolló discursos xenófobos tanto en los debates legislativos de las constituyentes de 1917 como en la legislación posterior sobre extranjería. Para este autor, que ha estudiado la inmigración extranjera en relación a la cultura política mexicana antes, durante y tras la revolución, México debía protegerse de los extranjeros porque la nacionalidad mexicana era a principios del siglo XX todavía muy débil. Yankelevich establece, por tanto, una relación estrecha entre el nacionalismo revolucionario y la xenofobia estatal. No todos los extranjeros eran igual de nocivos, sin embargo. Había extranjeros deseables y no deseables en función de su capacidad o incapacidad para integrarse en la nacionalidad mexicana. Esto explicaría la especial animadversión que la revolución mostró en algunos momentos hacia los españoles bajo acusaciones que ya se habían esgrimido a lo largo del XIX: abusos económicos, colaboración con el gobierno de Porfirio Díaz y otros. La hispanofobia, definida por la RAE como el rechazo a lo hispano o español, se justificó, pues, por la presencia e intervención de los españoles en la vida política y económica del país y por el funesto legado de la conquista y la colonia. Se articuló en la doble vertiente de afirmación del carácter no hispánico de la nación mexicana y de odio a los españoles que vivían en México, y afloró especialmente en momentos de crisis política interna, en forma de ataques a bienes de españoles e incluso en asesinatos y expulsiones.
} 
adquirieron poder de negociación con ellas sobre los términos de una integración social, económica y política de los inmigrantes que respetara su nacionalidad de origen y su identidad cultural ibérica. El acceso a personajes políticos de primera plana, la actividad de mediadores que incluía negocios con el Estado, redes clientelares étnicas y defensa de intereses de connacionales, fueron algunas de sus prácticas (Devoto, 2003: 315).

Por otro lado, bajo el empuje de los líderes étnicos de las comunidades españolas, se fue configurando un movimiento asociativo que fue creciendo con el tiempo hasta hacerse muy numeroso y variado. Los españoles fundaron o se afiliaron a una plétora de asociaciones voluntarias (Rueda Erranz, 2008: 36). ${ }^{3}$ José C. Moya afirma que el principal estímulo para la actividad asociativa no derivaba del background cultural de los inmigrantes o de los hábitos cívicos de los anfitriones, sino que tenía un origen más universal: el proceso migratorio mismo, que tendía a "intensificar y agudizar las identidades colectivas basadas en constructos nacionales, étnicos o cuasi étnicos". Hay que considerar que el fenómeno migratorio engendraba disrupciones que agregaban un fuerte estímulo a las organizaciones: situaciones en las que ni las instituciones tradicionales - los grupos de parentesco o las parroquias-, ni las más nuevas - como el Estado de bienestar o las corporaciones-, pudieran satisfacer necesidades sociales como el cuidado de la salud, el ocio o la camaradería (Moya, 2008: 11-12).

La actividad asociativa de los inmigrantes contribuyó a crear, reproducir y fortalecer materialmente los lazos intracomunitarios. Pero, además, resultaba imprescindible reforzar las solidaridades prácticas apelando a discursos que reafirmaran la existencia de una identidad española, aglutinante y complementaria de las diferentes identidades regionales y que trascendiera los vínculos utilitarios que definían la mayor parte de sus instituciones societarias.

Era, pues, necesario desplegar una acción cultural que, lejos de desentenderse de intereses concretos, incidiera positivamente en el estatus, la autopercepción y las condiciones materiales de existencia y reproducción de las colectividades. Como decíamos al inicio, esta acción debía ser capaz de impactar en el campo cultural y en la opinión pública de los países de acogida tanto como de España, para lo cual había que encontrar puntos de intersección en el intrincado y a menudo contradictorio entramado mental e ideológico español, entre sus discursos innovadores y los conservadores, los más agresivos y los defensivos, incluyentes y excluyentes, con el fin

\footnotetext{
${ }^{3}$ Una estadística de 1929 calculaba en unas mil doscientas sociedades, más de la mitad en Argentina, algo más de doscientas cincuenta en Cuba, cerca de sesenta en Estados Unidos, cincuenta en Brasil y cuarenta en Uruguay.
} 
de satisfacer razonablemente al público inmigrante sin ganarse la animadversión de la sociedad de acogida o el público metropolitano español (Duarte, 1998: 112). ${ }^{4}$

Ahí donde logró establecerse una comunidad migratoria, por pequeña que esta fuese, sus sectores letrados solían alcanzar enseguida cuotas considerables de liderazgo comunitario y a menudo lograban insertarse aceptablemente en espacios clave en las sociedades receptoras como la educación, las profesiones liberales o la prensa nacional, lugares desde los cuales podían abrirse espacios de interlocución con las élites latinoamericanas y también con las españolas (Núñez Seixas, 2003: 347-388). Estas últimas debían apreciar la importancia de los colectivos migratorios para el progreso futuro de España, así como los réditos diplomáticos, comerciales y de otros tipos que podían resultar de elevar el prestigio español en los países americanos.

La ciencia y la cultura, en este sentido, recorrieron caminos paralelos en España y América Latina en la coyuntura finisecular y en las primeras décadas del siglo XX. Las élites políticas e intelectuales de las Repúblicas americanas y de España tuvieron puntos de contacto en torno a las ideas del hispanoamericanismo, fuera en su vertiente progresista o conservadora (Niño, 1993:15-48, Dalla Corte y Prado, 2006: 195-216). ${ }^{5}$ Desde los gobiernos se potenciaron programas de intercambio cultural que alcanzaron importancia creciente con las visitas que se dispensaron intelectuales de uno y otro lado del Atlántico. Los inmigrantes apuntalaron la presencia española en el continente y desde sus asociaciones, empresas y lazos políticos y sociales, participaron en el desarrollo del movimiento hispanoamericanista (Sepúlveda, 2005: 337-339).

Para articular este tipo de intervenciones culturales y poner en circulación discursos funcionales que fomentaran la cohesión, la consolidación del mundo asociativo y la jerarquía dentro de las colectividades, era necesario dotarse de instrumentos eficaces de intervención en el mundo cultural y la opinión pública

\footnotetext{
${ }^{4}$ Como afirma Ángel Duarte, el precio para convertirse en un referente de la comunidad migratoria española era saber mantener "la moderación en el tono".

${ }^{5}$ La Real Academia Española define el hispanoamericanismo como la "actitud que tiende a reconocer y fomentar los valores de los pueblos hispanoamericanos". Véase www.rae.es [última consulta 18.12.2017]. Antonio Niño considera a esta corriente intelectual como una manifestación del regeneracionismo finisecular español, fenómeno ideológico hipercrítico fruto del enorme descontento político de las clases medias españolas, sobre todo las capas profesionales e intelectuales, con el Estado de la Restauración, por su incapacidad para solucionar el bloqueo de la modernización estatal y social española. Isidro Sepúlveda, por su parte, define el hispanoamericanismo como un movimiento cuyo objetivo era la articulación de una comunidad trasnacional sostenida en una identidad cultural basada en el idioma, la religión, la historia y las costumbres o usos sociales. Una comunidad imaginada que reunía a España con el conjunto de Repúblicas americanas, otorgándole a la antigua metrópoli un puesto primordial bajo la extendida expresión de "madre patria". Como ya sucediera con el regeneracionismo, el hispanoamericanismo tuvo sus variantes ideológicas, que diferían en los medios y los contenidos políticos y en los grupos que debían protagonizar la empresa trasnacional hispanoamericana, de modo que se suele hablar de un hispanoamericanismo reformador (institucionalista, positivista y krausista) frente a otro conservador (historicista y defensor del orden social).
} 
latinoamericana allí donde estos no existían. Por tanto, las asociaciones se esforzaron por abrir canales institucionalizados de intervención cultural, sobre todo las sectoriales - asistencialistas, recreativas, profesionales- que abrían, de forma paralela a sus actividades específicas, agendas culturales destinadas a atraer nuevos miembros e incluso, a menudo, a un público no español. Por otro lado, surgieron distintos tipos de asociaciones específicamente culturales o patrióticas, de matriz regional o nacional, fundadas para la difusión y defensa de la cultura ibérica. En estos proyectos se involucraron intelectuales, viajeros procedentes de España, y también las élites económicas de las comunidades en el financiamiento de las iniciativas culturales (Blanco y Dacosta, coords., 2014).

Más allá de la necesidad de obtener o consolidar el prestigio a través del mecenazgo, la inversión en la acción cultural por parte de los poderes fácticos de la emigración solía serles redituable y favorecía el tejido de redes sociales con las élites de los países de acogida. Así pues, para García Sebastiani la acción cultural de la emigración española necesitaba no solo utilizar intensivamente los locales sociales o los espacios públicos sino también "plataformas estables de control comunitario y proyección pública", para llegar también a la parte de las comunidades que no participaba de la vida asociativa (2005: 147).

Aquí aparece con toda su importancia la prensa étnica, como instrumento de las élites de la inmigración y del movimiento asociativo ¿Para qué? En general, para poder influir en la movilización de las colectividades españolas y poner en circulación discursos destinados a reforzar la cohesión identitaria y legitimar la organización institucional comunitaria hacia dentro; en particular, para presentar adecuadamente argumentos con el fin de negociar los términos de la integración en la sociedad de acogida sin una total asimilación; para obtener el reconocimiento moral y político de España y su tradición cultural de cara al exterior. Y, desde fines del siglo XIX, a estos objetivos se unió la expresión de los ideales hispanoamericanistas a través de los principales escritores de las comunidades migratorias.

La prensa étnica española en América Latina, fuera regional o nacional, jugó un notable papel como estrategia de intervención cultural y defensa de los intereses de la colectividad. Para entender su desarrollo hay que tener en cuenta tanto los requerimientos de un mercado étnico -allí donde el impacto de la inmigración permitió la conformación de un público demandante de información y cultura española - como la expansión de los mercados culturales latinoamericanos. La confluencia entre ambos permitió el afloramiento exitoso y la prolongada pervivencia de una opinión pública en la inmigración española en América (Garabedian, coord., 2017: 21-24). 
Con el tiempo, la prensa de los inmigrantes se hizo muy útil para organizar la vida comunitaria y retroalimentar el asociacionismo. Las colectividades veían sus ventajas en su segmentación, flexibilidad y diversidad de ámbitos de interés e intervención. Desde los órganos impresos de las asociaciones, nacidos para satisfacer las necesidades internas de comunicación, hasta las grandes publicaciones periódicas de circulación abierta, la prensa atrajo la inversión de las asociaciones, de emprendedores y capitalistas de la inmigración por su rentabilidad económica y su utilidad social, política e ideológica (Torricelli, 2017: 157-179).

La prensa étnica ofreció a su público crónicas de la vida asociativa y comunitaria; informaciones funcionales a los inmigrantes sobre la sociedad local, de índole geográfica, política, económica, laboral o legal; opiniones y análisis de la actualidad española; canales de expresión para la creación de una opinión pública propiamente española y un espacio publicitario para apuntalar el mercado étnico local. Enriquecía la vida asociativa al promocionar actividades recreativas o conmemorativas y movilizar a los españoles en beneficio de diferentes causas. Además, la prensa étnica acometió la promoción de la cultura hispánica, difundiendo novedades literarias, artísticas y científicas, convocando concursos literarios, celebrando efemérides de españoles ilustres, sosteniendo discursos de confraternización panhispánica en los que se situaba España como la madre o hermana mayor de jóvenes naciones surgidas de su imperio $y$, sobre todo, actuando como medio de acción cultural en los países de acogida.

El universo de la prensa española en América fue amplio, heterogéneo y dio lugar a una diversidad de publicaciones -boletines, revistas, periódicos, suplementos- y a una variedad de objetivos, líneas editoriales, formatos, radios de circulación, tasas de supervivencia relacionadas con la evolución de su público, de la colectividad, del mundo asociativo, de la disponibilidad y compromiso de las élites letradas, de los inversores, del mercado étnico y de los diversos condicionantes políticos, legales y económicos locales que afectaron a las empresas periodísticas españolas.

Estos fenómenos fueron recurrentes tanto en la prensa étnica española como la de otras nacionalidades (Baily 1999: 177-179, 195-197). La volatilidad de la mayoría de las cabeceras no afectó de forma estructural a la supervivencia de una información y opinión propiamente españolas en los contextos migratorios americanos; siguió siendo frecuente que, ante las dificultades o fracasos en estabilizar empresas periodísticas, se renovara la apuesta recreando proyectos similares en el corto o mediano plazo. Hubo en definitiva, una voluntad renovada de sostener medios de comunicación propios por la importancia estratégica que poseía la prensa étnica para la reproducción de la colectividad y su integración en el ámbito cultural americano. 
Algo similar sucedió en las empresas periodísticas de la colectividad española establecida en México en la época de la revolución y la posrevolución, de lo cual nos ocuparemos a continuación.

\section{Características de la emigración española en México}

Antes de analizar el periodismo español en México merece la pena hacer una breve alusión a la colectividad española allí radicada. Durante cinco siglos el flujo de llegadas de españoles a México fue ininterrumpido, aunque casi siempre se trató de una corriente migratoria pequeña, según ha destacado C. Lida (2006: 121). La pauta de llegadas a cuentagotas permaneció vigente desde fines del siglo XIX y a lo largo del siglo XX, a excepción tal vez del traslado masivo y concentrado en pocos años de los exiliados de la Guerra Civil.

Se ha de enfatizar, en primera instancia, en el hecho de que los extranjeros nunca han alcanzado cifras significativas en México, sino más bien al contrario, el país adquirió pronto el carácter de expulsor de población. A lo largo del siglo XX la proporción de extranjeros que arrojan los censos nacionales en ningún momento ha superado el $1 \%$ respecto a la población total mexicana. Al finalizar el período porfiriano (1876-1910), los mexicanos alcanzaban la cifra de quince millones de habitantes, mientras que el total de inmigrantes de origen español registrados en el Tercer Censo General de 1910 apenas Ilegaba a los treinta mil, es decir, un escaso 0,2\% del total de la población (porcentaje que tendió a disminuir desde entonces). Con todo, constituían la minoría extranjera numéricamente más importante en ese tiempo, lo cual representaba poco más de un cuarto del total de extranjeros que vivía legalmente en México (Gil Lázaro, 2015: 32-55).

A partir del estallido de la revolución el flujo migratorio fue negativo y persistió así hasta 1917. El Cuarto Censo Nacional de 1921 muestra que la población española residente en México tuvo un crecimiento negativo de casi diez puntos, en su mayoría concentrados en las vísperas de la Primera Guerra Mundial. La disminución se explica por el retorno a España pero también por procesos de reemigración a países vecinos como Cuba y Estados Unidos. En el siguiente registro censal, el de 1930, la presencia de inmigrantes españoles casi había recuperado los índices previos a la guerra. Este Quinto Censo Nacional mostró que en el país residían 47239 españoles de uno y otro sexo y de todas las edades. El mayor crecimiento se dio a mediados de la década de 1920, por la salida masiva de jóvenes en edad militar, que escapaban de la guerra 
colonial española en Marruecos. ${ }^{6}$ El declive en las llegadas de inmigrantes comenzó en 1929 hasta interrumpirse del todo en 1936-1937 por la Guerra Civil española.

Hay que señalar que la inmigración española a este país tal vez sea más parecida a la de muchos otros países del continente en cuanto al flujo pequeño pero constante de inmigrantes que llegaron desde los siglos coloniales hasta los años treinta. Las cifras de españoles en el exterior de Jordi Maluquer para el año 1930 permiten estimar en torno a 1671588 el número de españoles residentes en el continente americano en ese año, de los cuales un 2,8\% residía en México. El país ocupaba el sexto lugar en recepción de inmigrantes hispánicos pero a mucha distancia de los cinco anteriores (2007: 145).

El asentamiento de los españoles a lo largo de las cuatro primeras décadas del siglo XX se caracterizó por una enorme dispersión en México. El principal lugar de llegada fue la ciudad de México, seguida de otras ciudades como Veracruz, Puebla, Chiapas, Sonora, Chihuahua, Coahuila, Yucatán, Tamaulipas y Nuevo León. Al igual que otros grupos extranjeros, quienes desde fines del siglo XIX emigraban por motivos esencialmente económicos, los españoles eran sobre todo hombres jóvenes solteros que pertenecían por regla general a estratos sociales bajos. Conformaban en su mayoría una mano de obra jornalera del campo y la ciudad o, en el menor de los casos, de artesanos más o menos cualificados y de pequeños agricultores y pastores.

Provenían de las regiones cantábricas, vascas, catalanas y castellanas. Según los datos del Registro Nacional de Extranjeros, las principales provincias fueron Asturias, Santander ( 21 y 17\% respectivamente), seguidas de lejos por Vizcaya, Barcelona, León y Burgos (Lida, 1997: 68). La llegada e inserción de los españoles tuvo lugar por medio de la reanudación de cadenas migratorias - algunas de las cuales se remontaban incluso al virreinato- y también por la expansión de nuevas redes de familiares, paisanos y amigos que facilitaron al recién llegado su primera instalación en México, la obtención de un puesto de trabajo y el inicio de un lento pero probable proceso de movilidad social ascendente (Sánchez Albornoz, 1988: 13-29).

Desde el porfiriato, un pequeño sector de la comunidad española destacó por un alto nivel de acumulación de capital en la propiedad y producción agrícola, en la industria -especialmente textil y metalúrgica-, en el comercio y la banca, que incluyó bancos locales, regionales e incluso nacionales. Sin embargo, el nicho laboral por excelencia del grupo se situó en el pequeño comercio de abarrotes, pulquerías y tabernas, que popularizaron la imagen del "gachupín" asociada a un estereotipo de carácter negativo, larga trayectoria y origen incierto (Gil Lázaro, 2006: 367-399). EI RNE

\footnotetext{
${ }^{6}$ El estudio de Lida a partir del Registro Nacional de Extranjeros (RNE) muestra que los inscritos hasta 1936, todos ellos mayores de quince años, ascendían a unos treinta mil (Lida 1997: 60-74).
} 
estudiado por Lida muestra que un $43 \%$ se dedicaba a actividades comerciales, industriales y financieras y un $16 \%$ a trabajo doméstico no remunerado. Casi un $26 \%$ era población asalariada en los sectores mencionados (Lida 1997: 60-61). La autora concluye que, en general, el empleo como dependientes, jornaleros y artesanos se impuso claramente sobre la categoría de propietarios y negociantes acomodados.

Los sectores más acomodados crearon sus propias instituciones, entre las que destacaron por su precocidad en el contexto americano las de carácter asistencial, bajo la fórmula predominante de Sociedades de Beneficencia. Estos organismos representaban el tradicional modelo caritativo heredado del Antiguo Régimen, con un importante componente religioso en su matriz ideológica (Gil Lázaro, 2016: 79-104). Junto a las instituciones benéficas, los casinos, cámaras de comercio y clubes deportivos y de ocio, a menudo de marcado carácter regional, completaban la nómina asociacionista de esta inmigración económica tradicional en México. Estudios recientes a partir de fuentes impresas muestran además la presencia y dinamismo de asociaciones de empleados de comercio (Gutiérrez Domínguez, 2016: 195-216).

\section{La prensa española en México en el primer tercio del siglo XX}

Las relaciones culturales entre México y España han constituido un tema recurrente en la historiografía de ambos países desde la independencia hasta el presente, incluida la vertiente del periodismo. Sin embargo, aún no se ha realizado un estudio en profundidad de la actividad intelectual y editorial de la colectividad española en las décadas revolucionarias y posrevolucionarias, pese a que la historiografía sí ha hecho uso de la prensa y escritos de inmigrantes intelectuales para abordar cuestiones centrales de las relaciones entre las dos naciones -diplomacia, negocios o flujos migratorios-. ${ }^{7}$

¿Por qué razón este periodismo español de principios del XX aún no ha sido abordado como objeto de estudio histórico? En el libro que Pablo Mora y Ángel Miquel coordinaron en 2008, Españoles en el periodismo mexicano, siglos XIX y XX, no se incluyen trabajos referidos al tiempo posterior a la revolución y previo a la llegada del

\footnotetext{
${ }^{7}$ Así, la reacción de la prensa nacional y regional en España sobre la revolución mexicana ha sido muy estudiada (Delgado 1993; Sevilla 2015; Beltrán 2007); también las narraciones que ofrecieron escritores y viajeros españoles en México como Valle-Inclán, Blasco Ibáñez, Araquistaín o Domingo (Delgado 1992; Matute 2012). Pero no ha sucedido lo mismo respecto a la prensa de los inmigrantes en México.
} 
exilio. 8 Los autores explican que la prensa española en dicho lapso se dirigió exclusivamente a la colonia de residentes peninsulares y se mantuvo en terrenos tales como "la crónica de espectáculos o las actividades de beneficencia, el desarrollo empresarial y la vida social de la comunidad hispana" (2008:17; 2006: 221-233). La escasez de publicaciones, el perfil localista y superficial de sus contenidos o en general la magra calidad de la prensa española durante estos primeros decenios, habrían podido inhibir, pues, la atención de los historiadores.

Paradójicamente, los autores citados reconocen que esta labor periodística no fue sino una prolongación de la de las últimas décadas del siglo XIX, con lo cual muchos de sus integrantes tenían ya una amplia trayectoria laboral en el país a principios del XX. La revolución, por su parte, no haría sino profundizar ciertas pautas de larga duración de esta prensa: "la inestabilidad de las pequeñas empresas que la constituían, los cambios frecuentes de dueño, director y redacción y la orientación a dar noticias de España y comentar las actividades realizadas por los españoles en México" (2008:193).

Si bien todo esto es cierto, habría que añadir, sin embargo, que el periodismo español de estas décadas contempló e interpretó los acontecimientos mexicanos; narró cómo la colonia española los vivió y cómo afectaron a las relaciones entre los dos países. El relato de estos hechos desde el punto de vista español a través de distintos canales de expresión, configura en nuestra opinión un tema para la investigación. A esto debe añadirse que las narrativas periodísticas que estudiamos se desenvolvieron en un marco cultural más amplio compartido a ambos lados del océano, el cual confería otra dimensión al localismo percibido anteriormente. La raigambre hispanoamericanista en los discursos de autores españoles en México justifica también el estudio.

Estas páginas suponen una primera aproximación al periodismo español durante la revolución y posrevolución. Para abordarlo hemos establecido una periodización: en primer lugar se describen los precedentes, es decir, la configuración de la prensa y la producción intelectual de los españoles durante la etapa porfiriana, especialmente en sus últimos años. A continuación se abordan los principales temas que preocuparon a los periodistas inmigrantes en los años de lucha armada de 1910 a 1920 así como en las dos primeras décadas posrevolucionarias.

\footnotetext{
${ }^{8}$ Este libro constituye el único texto de análisis historiográfico publicado hasta el momento en el que el tema central es el periodismo español en México. Dos años antes, Mora y Miquel editaron otro libro de muy cuidada factura que recogía los principales materiales de una exposición realizada con motivo del setenta aniversario del inicio de la Guerra Civil: Barco en tierra. España en México (2006).
} 


\section{Precedentes}

Las primeras publicaciones periódicas españolas en México aparecieron poco después de la reanudación de relaciones diplomáticas, en la década de 1840 . Entre 1873 y 1910 más de una veintena de publicaciones se dirigían a una comunidad que a la altura de 1900 apenas sobrepasaba los dieciséis mil individuos (Toussaint, 1993). Algunas de ellas databan de las décadas previas a la llegada de Díaz al poder, como La Iberia (1867-1876), fundada por Anselmo de la Portilla y La Colonia Española (18731879), creada por Telésforo García y Adolfo Llanos y Alcaraz (Gutiérrez 2008). Otros aparecieron ya durante el Porfiriato, como El Centinela Español (1879-1882), que sustituyó al anterior tras la expulsión de Llanos, y El Pabellón Español (1883-1890), dirigido por el granadino Ramón Elices Montes, quien había sustituido a García en 1881 como director de El Centinela Español (Vieyra 2008; Mora 2008).

Los últimos años del porfiriato constituyeron, según Armando de María y Campos, un momento importante para la prensa étnica, con diarios que competían entre ellos y que nutrieron distintos debates, no solo dentro de la colonia lectora sino también en la esfera mexicana, como la guerra colonial y el desastre del 98 en Cuba (1960: 86-88). ${ }^{9}$ El periódico español más emblemático y longevo de esta etapa fue $E I$ Correo Español, fundado en 1889 por Fernando Luis Juliet de Elizalde, quien además fue su editor, propietario y director. En 1900 el diario se convirtió en el órgano oficial de la Cámara de Comercio Española y en 1902 lo compró el editor asturiano José Porrúa. Bajo su dirección, hasta 1911, el diario alcanzaría cierta estabilidad (Figueroa Esquer, 1992). A comienzos de siglo aparecieron otros tres periódicos españoles que se disputaron al público lector de la colonia: La Nación española, Correspondencia de España y El Diario español, que se convirtieron en portavoces del sector letrado de la colonia, muchos de ellos auspiciados por las principales organizaciones asociativas del grupo, como hiciera el Casino Español de la capital mexicana respecto a La Iberia. En las páginas de estos diarios se desplegaron campañas hispanoamericanistas dirigidas a ensalzar la herencia española tanto como a reivindicar la pertenencia de México y de su antigua metrópoli a una misma raza y tradición cultural de carácter latino.

Luther N. Steward, estudioso norteamericano de la prensa étnica española del XIX, afirma que a pesar de esta actividad aparentemente febril para una comunidad tan pequeña, su producción periodística fue en realidad "débil, fragmentaria y de escasa rentabilidad económica". Las inquietudes de los inmigrantes lectores de diarios no se hallaban en la actualidad española que con notable empeño trataban de reflejar

\footnotetext{
${ }^{9}$ Hablamos de la "colonia lectora" aunque no estamos en disposición por ahora de dar una cifra de las tiradas de estos periódicos, del número aproximado de lectores o incluso de periodistas; cifras, en todo caso, reducidas y dependientes de una comunidad alfabetizada pero con escasas inquietudes intelectuales.
} 
sus diarios, realidad que a muchos se les antojaba lejana después de años de ausencia de su tierra. Su lealtad, más bien, estaba unida a sus negocios y se relacionaba con el contexto mexicano (1965: 432).

El impacto de esta etapa del periodismo español se debe calibrar de otro modo, por tanto. $Y$ es que la presencia de un nutrido grupo de periodistas y escritores españoles, perfectamente integrados en la vida cultural mexicana porfiriana, facilitó el estrechamiento de las relaciones culturales hispanomexicanas. De hecho, la actividad desplegada por autores como Anselmo de la Portilla, Niceto de Zamacois, Olavarría y Ferrari, Telésforo García o Concepción Gimeno, ha sido bien estudiada justamente porque trascendió los círculos periodísticos y literarios estrictamente españoles y se fusionó con la del grupo de intelectuales mexicanos en torno al pensamiento científico que inspiró la política porfirista. Esta situación facilitó la creación durante dicho período de varias redes intelectuales entre ambas orillas (Sánchez y Pérez, 2015).

\section{La etapa revolucionaria}

Una situación similar a la descrita se reprodujo, con variantes, en la siguiente etapa. Los autores más representativos del período compensaron la imposibilidad de alentar una mayor producción de periódicos y revistas propios de la colectividad con un animado trasiego de artículos, ensayos y obras literarias que circularon en la prensa mexicana tanto como en la peninsular e incluso la habanera. Esto fue posible gracias al despliegue de redes trasatlánticas de intelectuales en torno al hispanoamericanismo que se extendió desde fines del XIX y el primer tercio del XX. En este sentido, la continuidad fue la tónica respecto al período anterior.

En 1910, la colonia española en México alcanzaba los treinta mil integrantes, su tamaño máximo hasta entonces. A partir de ese momento, la estabilidad económica, social y política del grupo se puso en entredicho ante la oleada de violencia de la etapa revolucionaria. Esta no comenzó a remitir hasta el inicio de la década siguiente, lo cual dejó un rastro periodístico notable entre los escritores españoles residentes en México. A estas preocupaciones habría que añadir otras igualmente importantes como la crítica feroz de los acontecimientos revolucionarios y de sus adalides (que le valdría más de una expulsión de sus voceros), el lugar ocupado por el grupo migratorio en dichos sucesos y las consecuencias de ello en las relaciones entre España y México.

Tras la salida de Porrúa, El Correo Español pasó de mano en mano durante un tiempo hasta que asumió la gerencia y la dirección Lorenzo B. Serrano, a mediados de 1913. Para ese momento el diario ya había expresado veladamente su oposición al 
maderismo y su apoyo al ascenso del general usurpador Huerta - comentando con detalle los sucesos de la Decena Trágica, o denunciando los ataques revolucionarios a las propiedades españolas, por ejemplo- pero con la llegada de Serrano las simpatías al huertismo se hicieron explícitas. La abierta adhesión del diario a uno de los bandos en pugna provocó quejas reiteradas del ministro plenipotenciario. El periódico con Serrano al mando quedó como único portavoz del grupo y no suavizó su tono intervencionista a pesar de la oposición diplomática. Fue clausurado a fines de 1914, tras la caída del dictador Huerta y el destierro de su director (Mac Gregor, 2002:68). A principios de la década siguiente Serrano volvió para relanzar El Correo Español, sin mucho éxito. Los intentos posteriores de publicar otro periódico étnico se tornaron muy difíciles en los años revolucionarios y no fueron bien vistos por los diplomáticos españoles.

En resumen, durante la revolución el panorama de publicaciones periódicas españolas fue muy reducido $y$, salvo excepciones, homogéneo ideológicamente, conservador y contrarrevolucionario, acorde al perfil del grupo al que iba dirigido y que lo sostenía. Sucesos como los asesinatos de españoles en el norte mexicano, las exacciones de los jefes revolucionarios impuestas a los propietarios extranjeros en la ciudad de México o las humillaciones que las autoridades infringieron a los comerciantes españoles de la ciudad fueron noticia en las cabeceras españolas del país.

Por otro lado, fuera del ámbito de la prensa de carácter informativo, en la segunda mitad de la década de 1910 se crearon varias revistas de contenido cultural con aportaciones de periodistas y literatos de ambos lados del Atlántico. En 1916 apareció Rojo y Gualda, fundada por el poeta asturiano Alfonso Camín; colaboraban Ricardo de Alcázar (Florisel) y Felipe Velasco (Don Nadie), quienes después fueron sus editores. La publicación se caracterizó por su carácter españolista - se autodenominaría "órgano espiritual" de los españoles en México-, por lo cual, aparte de su contenido literario y ensayístico, solía dar también en cada número algunas noticias de España. Sus artículos reprodujeron los enfoques ideológicos, políticos y culturales del hispanoamericanismo (Niño 1993:15-20). Rojo y Gualda fue la revista más duradera de este período, pero los mismos ideales se expresaron también en Castillos y Leones, otro semanario editado de nuevo bajo la iniciativa de Camín, tras la desaparición de la anterior. Entre 1918 y 1919 se publicaron, además, Tricolor con el escritor Julio Sesto al frente, y Don Quijote (1919-1922), semanario ilustrado editado por Atanasio Melantuche.

A falta de medios propios, la expresión más habitual del periodismo español fueron las colaboraciones en prensa autóctona. Los textos de muchos de los periodistas inmigrantes circularon regularmente en diarios como Excélsior y EI 
Universal y en semanarios como Revista de Revistas y El Universal Ilustrado. Prueba de la versatilidad de los escritores asentados en México es que sus aportaciones aparecieron también en la prensa española, en diarios como El Imparcial, $A B C$ (y su semanario Blanco y Negro), La Voz, El Sol, El Siglo Futuro o El Heraldo de Madrid. Algunas cabeceras contaban incluso con corresponsales en México, como el diario madrileño La Libertad, que durante años recibió colaboraciones de Alfonso Camín (Mora y Miquel, 2008:194).

En este panorama, un perfil cabal de escritor y periodista entre dos mundos lo ofrece Julio Sesto, quien publicó sus artículos en El Hijo del Ahuizote, Diario del Hogar, El Universal, Excélsior, Hoy, Mañana y Siempre y sobre todo en El Imparcial. Al mismo tiempo, en Madrid Sesto fue colaborador de Blanco y Negro, Nuevo Mundo, La Ilustración Española y Americana y El Liberal y en sus viajes a La Habana trabajó para EI Diario de la Marina y El Mundo llustrado. Otro periodista, muy unido a las instituciones asociativas, sobre todo la Casino Español, fue Florisel, quien entró muy joven en El Imparcial como corrector de estilo y más tarde en El Diario Español y El Dictamen. Más que ningún otro, este autor encarnó el esfuerzo por redimir a la colonia de su sempiterno ensimismamiento cultural, su estrechez de miras intelectuales y su incapacidad para generar proyectos periodísticos sostenibles. Sesto, Florisel y otros periodistas y escritores como Felipe Velasco, Pedro Serrano o Enrique Guardiola, encarnaron una generación de periodistas inmigrantes que desarrollaron su carrera íntegramente en México, es decir, no perdieron en ningún momento los lazos con el lugar de origen, pero publicaron la mayor parte de sus obras en el de acogida, involucrándose fuertemente con lo que en ellos sucedía sin abandonar el contacto con un periodismo peninsular ya dejado atrás. En sus argumentos se imponía una defensa a ultranza de España y los españoles, de la historia colonial, del papel de la colonia en el crecimiento de México, en la cultura compartida y los lazos de sangre.

A este grupo también pertenecía el palentino Desiderio Marcos, quien colaboró a través del envío de pequeños relatos y reseñas críticas a revistas españolas como Nuevo Mundo, Mercurio o La llustración Artística y a mexicanas como Cosmos. En su producción durante la etapa revolucionaria destacaron varios folletos críticos respecto al papel jugado por sus compatriotas durante la revolución, sobre todo su denuncia de los hechos que condujeron a la hambruna de 1915 en la capital mexicana en textos como Acaparadores y amoladores (1915). Aunque atípicos, estos ensayos breves que Marcos continuó publicando después del período bélico, no son sino un intento más, de los muchos que surgieron entonces, de defender la presencia española en el país frente al complicado contexto político mexicano. La defensa de la colonia se convirtió en estos años en un tópico entre los autores que vivían en México o visitaban el país 
ocasionalmente y que se reiteró bajo el formato de conferencias publicadas y folletos, tales como las de Baltasar Fernández Cué (1917) y Antonio Orts Ramos (1918).

Tras la desaparición de El Correo Español, el periodismo étnico se replegó y mudó el tono crítico anterior por uno francamente anuente con el nuevo régimen, que no escatimó elogios a la labor de los revolucionarios. Buen ejemplo de ello son los libros de viajes de Maximino Valdés (Conde de Fox), como Impresiones de México (1918), que contenía abiertas alabanzas al carrancismo, o la amistad posterior de Desiderio Marcos con el general Plutarco E. Calles, expresada en varias dedicatorias en sus textos al que fuera presidente del país entre 1924 y $1928 .{ }^{10}$

A la vez que elogiaba a la revolución, Marcos defendía la necesidad de las colonias extranjeras de unirse para sí y entre ellas para protegerse de sus desmanes. Así lo propugna en su texto México y los extranjeros, de 1922, y más tarde, a raíz de una propuesta asociativa lanzada al grupo, escribiría Liga española de defensa y protección en México, en la que criticaba el carácter clientelar y paternalista de las instituciones españolas, a la vez que proponía, como alternativa, un proyecto unionista "sin distinción de credos religiosos, ni políticos, ni categorías sociales y económicas" (1924). Dos años después en un nuevo folleto provocador acerca de la situación de los españoles: España México (guía de emigrantes) (1926), persuadir a los lectores desde España antes de que se animaran a emigrar.

En cierto modo, estos cambios no hacían sino reflejar esa actitud defensiva ya citada frente a la amplia corriente de hispanofobia que atravesó la década y que se manifestó con fuerza en las publicaciones periódicas mexicanas y en expresiones populares de violencia callejera. Según Tomás Pérez Vejo, la hispanofobia revolucionaria fue tan constante y persistente que no se puede explicar solo a partir de hechos coyunturales -la ubicación de los españoles en la vida económica mexicana o la debilidad de la política exterior española- sino que se trata de un asunto de mayor calado histórico que cobra sentido dentro del "complejo problema de las relaciones de México con España, lo español y los españoles a lo largo de sus dos siglos de vida independiente" (2010:11). Aunque las relaciones entre ambos países se normalizaron y los conflictos con la colonia se atenuaron, los discursos del nacionalismo revolucionario renovarían cada tanto el odio popular al gachupín y, con ello, la

\footnotetext{
${ }^{10}$ La reflexión de Marcos no se centró únicamente en los acontecimientos mexicanos sino que también publicó obras relativas a la política española, como el folleto de 1929 titulado Primo de Rivera no es tirano y es honrado: algunas ideas y observaciones de un libro futuro. En 1939 publicó El encanto de los pueblos españoles, en el que recuperaba el tema de la idealización de la vida rural que ya había desarrollado anteriormente y que en realidad servía a Marcos para defender el nuevo orden de cosas instaurado tras la Guerra Civil en España y la demonización del régimen republicano frente a los lectores mexicanos (De Hoyos 2012 y 2011).
} 
necesidad de los españoles de legitimar el lugar que ocupaban en México, tarea a la que se entregaron denodadamente los escritores inmigrantes.

\section{Continuidades y cambios en los años veinte y treinta}

A pesar de que los regímenes posrevolucionarios no pudieron acabar con las rebeliones militares hasta bien entrados los años treinta, se suele considerar la etapa que comienza en 1920 como de reconstrucción política, económica y cultural del país. Además, el radicalismo de los líderes políticos de este período hasta la presidencia de Lázaro Cárdenas, favoreció un clima de apertura social y libertad de expresión, así como de expansión de la educación, las letras, las artes y el periodismo. Esta libertad disminuiría a medida que el autoritarismo del nuevo régimen arraigaba, sobre todo durante el conflicto cristero en la segunda parte del mandato de Calles y también en los años posteriores del Maximato (Serna 2014:116).

La creación en los años veinte de algunos de los diarios mexicanos más importantes de este tiempo como El Universal o Excélsior, que mantenían secciones dedicadas a la colonia española y daban cabida a la información cablegráfica procedente de España y a la producción de los periodistas españoles establecidos en México o desde España, inhibió las iniciativas periodísticas de los españoles. Solo un periódico étnico logró sobrevivir: el vespertino independiente El Día Español (19191933). Fundado por Ricardo de Alcázar, en 1921 logró abrir su propio taller de impresión, en 1924 se convirtió en un diario matutino y dos años más tarde el escritor decidió venderlo, cuando el cónsul español Carlos Badía Malagrida entró como socio en la empresa con el fin de relanzarla (Bada, 1951:32).

El periodismo español fue activo, por el contrario, en las iniciativas editoriales mexicanas. Según Beatriz Urías, ya desde principios de la década de los veinte circulaba en México una prensa periódica autóctona marcadamente hispanófila, como El Heraldo de la Raza, América Española y Acción Española. Los autores que escribían en ellas, españoles y mexicanos, lo hicieron también en revistas españolas como La Gaceta Literaria y Unión Iberoamericana (2010:199).

Fuera del periodismo informativo, las iniciativas españolas dieron muestra de la firmeza de las redes e intercambios entre España y México. Florisel fundó una revista literaria La Voz Nueva, publicada entre 1927 y 1931, que fue el proyecto que más le acercó a los círculos intelectuales mexicanos de su generación. Por sus páginas desfilaron autores como Salvador Novo, Bernardo Ortiz de Montellano, José Gorostiza o Xavier Villaurrutia. No fue la única oportunidad de compartir cartel con los poetas y 
novelistas de la generación de los Contemporáneos. En 1930 apareció una nueva revista, El Espectador publicada solo ese año, con periodicidad semanal y el poeta español Humberto Rivas como director. La revista tuvo incidencia sobre el panorama teatral mexicano y por ella circularon los más importantes dramaturgos del momento (García-Sedas, 2009:93-94).

La mayor parte de la obra de Florisel estuvo dedicada a la crítica y a la exégesis aunque también publicó su producción poética. Sin duda De Alcázar fue el escritor más fecundo de la colectividad y era conocido también como conferencista y traductor. En algunos de sus ensayos demostró su devoción castiza por la lengua castellana peninsular, Por el alma y el habla de Castilla (1922) o Cómo hablamos en México (Sintaxis sin tasa oral y escrita cogida al vuelo) (1944). Otro de los tópicos esenciales de su obra fue la defensa de la historia colonial española en América frente a la creciente influencia cultural de los Estados Unidos, en obras como El cuento y la cuenta del oro de América (1933). También le preocupó la defensa de la colonia española de México en El cetro, las cruces y el caduceo (en busca de la conciencia de la colonia) (1928) o El gachupín. Problema máximo de México (1934), al tiempo que criticaba la fragmentación de sus instituciones asociativas en Unión, fusión y confusión de la colonia (un esquema de superestructura racional) (1928).

Con un sentido más localista, una parte de la producción escrita española de estas décadas se elaboró dentro de las plataformas asociativas de la comunidad. El fin del conflicto armado permitió una vuelta a la normalidad de las instituciones, la proliferación de otras nuevas y el crecimiento del tejido societario de carácter regional, al tiempo que crecieron las divisiones internas y las fricciones (Gil Lázaro, 2014). Estas publicaciones no tuvieron especial impacto más allá de las fronteras de la asociación que representaban: Acción Española. Revista Hispano-mexicana (1924-1927) estaba ligada al Centro Gallego y a la Unión Montañesa; Acción Económica. Revista mensual hispanomexicana, constituyó el órgano oficial de la Cámara Oficial Española de Comercio, Industria y Navegación (1924-1928) y España. Revista bimestral (fundada en 1923), fue la publicación del Club España de México. Muchas de estas publicaciones se entregaron en el tiempo posrevolucionario a una labor panegirista del nuevo régimen, cuyo fin último era en realidad defender los intereses de la inmigración española en México y ahuyentar las oleadas de antigachupinismo que permanecían en estado latente y renacían puntualmente en momentos de crisis económicas o diplomáticas.

La llegada del régimen político republicano en España y la Guerra Civil fueron acontecimientos vividos con intensidad en las comunidades españolas en América y la producción periodística étnica volcó su mirada y su quehacer más que nunca hacia lo que acontecía en el país de origen, sin abandonar totalmente la orientación local y los intereses de las comunidades a las que informaban. La española dejó de ser una 
comunidad ideológica y socialmente monolítica gracias al aumento de simpatizantes y militantes republicanos - sobre todo nacionalistas vascos y catalanes, así como algunos asturianos-, quienes abrieron una fisura que se reflejó en la prensa y las publicaciones sobre todo en la ciudad de México. Así, un cisma en el Centro Vasco llevó a la creación de un grupo paralelo anti republicano, el Círculo Vasco Español, que hizo públicas las causas de su segregación en el texto La querella de los vascos en México (1935).

Los órganos de difusión de la colonia en los años treinta fueron El Diario Español, que solo aparecía tres veces por semana y los semanarios Vida Española y La Semana Española, alineados con el sector más recalcitrante del grupo, contrarios a la República y, a partir de 1936, adeptos a la España nacional. Por su parte, los periódicos El Popular, El Machete, y la Gaceta Española defendieron a ultranza la causa republicana. La prensa española en México que apoyó al bando rebelde sobrepasó con mucho el número de ejemplares de la prensa pro republicana (Pérez Montfort, 1992:150).

Con la llegada de los exiliados, la comunidad española recibió un repentino y cultivado aporte que hizo renacer la actividad periodística bajo nuevos ejes, muy distintos a los que habían predominado hasta entonces. Obviamente la dicotomía entre la antigua y esta nueva colonia española se trasladó al periodismo. La presencia de los escritores del exilio inauguró, por tanto, una nueva etapa para el periodismo español en México, considerada una nueva cima y que ha sido muy bien analizada por lo que no nos detendremos a examinarla (Miquel, 2008: 194-195). ${ }^{11}$

Los años cuarenta estuvieron marcados por la difícil convivencia entre los recién llegados, periodistas de gran prestigio algunos de ellos, comprometidos con la causa republicana, y los intelectuales inmigrados, afines al conservadurismo propio de la colonia y adheridos desde un inicio al bando vencedor de la guerra. El brillo intelectual del exilio ha hecho que el "viejo" periodismo español de las décadas posteriores a la guerra haya quedado opacado en la historiografía reciente, a pesar de la estrecha relación que se estableció en algunos casos entre la derecha mexicana hispanófila y la intelectualidad de los antiguos residentes.

\footnotetext{
${ }^{11}$ El periodismo del exilio se convirtió, según Ángel Miquel, en uno de los principales vehículos de expresión, identidad y defensa del grupo llegado a México. Publicaciones destinadas a la cohesión de sectores específicos, algunos efímeros y otros de largo recorrido, compartían todas ellas un mismo reto "cómo enfrentar, a la distancia, al gobierno enemigo de Franco" y de cómo unir a los exiliados de cara a un probable retorno futuro a España. Las revistas fundadas por exiliados dieron entrada no solo a los intelectuales españoles desterrados sino a hombres de letras latinoamericanos. Las empresas periodísticas de carácter cultural sobrevivieron en el tiempo mientras que las plenamente políticas, afianzado el régimen dictatorial dentro y fuera de España, se fueron extinguiendo.
} 
La actividad de los periodistas inmigrantes continuó, en algunos casos muy influida por el falangismo y sobre todo por la prédica de la hispanidad, la doctrina lanzada por los propagandistas del franquismo que pretendió sustituir al ideario hispanoamericanista. En 1940, aparecería en México el Boletín de Unidad para la colonia española dirigido por el falangista José Castedo. A partir del número 33, la revista se convirtió en Hispanidad, voz de España en América. En los años cuarenta, las diferentes corrientes hispanófilas hicieron oír su voz en los periódicos Excélsior, El Universal, El Hombre Libre, Omega, Orden y en las revistas Lectura, Ábside, La Nación, Panorama, Jerarquía y Unidad. El discurso de la hispanidad se abrió camino a través de diversos autores entre los que destaca Emilio Lanzagorta, empresario metido a escritor y propagandista, quien publicó sus conferencias en 1949 con el título Hispanidad en México.

\section{Consideraciones finales}

En estas páginas hemos intentado mostrar cómo la prensa de los inmigrantes españoles en México en el primer tercio del siglo XX intervino en el mundo cultural para conformar redes sociales y sostener prácticas e ideas alentadas por el pensamiento hispanoamericano. A pesar de los vaivenes políticos en las primeras cuatro décadas del siglo, los periodistas españoles hicieron un esfuerzo notable por canalizar una identidad hispana y unas ideas hispanoamericanas a través de su producción escrita.

Una de las primeras constataciones a las que se ha aludido en estas páginas es que el periodismo español de principios del siglo XX mantuvo una línea de continuidad, tanto en los medios impresos como en las inquietudes intelectuales, respecto al período porfiriano. Se trató de un periodismo a la defensiva, tanto su visión de la colectividad a la que representaban como en el lugar que ocupaban frente a la sociedad de acogida. El proceso de construcción nacional mexicano a partir de 1910 mostró, entre sus características básicas, un rechazo frontal a la herencia colonial hispana, al tiempo que dirigía la mirada hacia el pasado prehispánico. Sin embargo, aunque las relaciones entre ambos países se normalizaron tras la revolución y los conflictos con la colonia se atenuaron, los discursos del nacionalismo revolucionario renovarían cada tanto el odio popular al gachupín y, con ello, la necesidad de los españoles de legitimar el lugar que ocupaban en México, tarea a la que se entregaron con ardor los escritores inmigrantes.

Como analizamos al inicio, el periodismo español en América Latina fue una constante, una necesidad y un medio de expresión de la identidad. El periodismo 
español en México no quedó al margen del vendaval revolucionario, sino que se sumergió en él, lo criticó, tomó partido y sufrió, por tanto, las consecuencias. El conflicto acabó con el dinamismo periodístico de los españoles que había caracterizado la primera década del siglo y con las condiciones de posibilidad de sostener una prensa propia. Si pudo apenas sobrevivir en coyunturas tan conflictivas de la historia mexicana como esta fue debido a la renuncia a la autonomía en sus empresas periodísticas y la participación plena en las ajenas, fueran mexicanas o peninsulares. Las que existieron, escasamente financiadas y por tanto poco longevas, como El día español de Florisel en los años veinte, compitieron en condiciones muy desventajosas con el auge abrumador de la prensa mexicana de tirada masiva, que arrastró en su crecimiento a las pequeñas iniciativas de la colectividad española.

El principal destinatario de la prensa española fue siempre la escasa colonia de inmigrantes residente en este país y su aún más escasa franja de lectores, lo cual, frente a las experiencias periodísticas españolas en otros países receptores de población española, como Argentina o Cuba, impuso claros límites a su expansión. Los periodistas y empresarios del periodismo se vieron obligados, por tanto, a abandonar los canales clásicos de la prensa, lo que no impidió la práctica cotidiana del periodismo. Tal vez la única línea divisoria clara de este periodismo en toda la etapa independiente pudo ser la llegada de los periodistas del exilio. Existe, sin embargo, una línea de continuidad entre el periodismo de los inmigrantes tradicionales y la articulación de un discurso de la hispanidad que se exportó a América Latina a través de los propagandistas del franquismo. Esta línea de análisis no ha sido aún explorada y merecería la pena ahondar en ella.

Independientemente de la calidad o cantidad de los diarios, revistas o folletos y del alcance o influencia de los temas tratados, los autores y obras aquí reseñadas dan cuenta palmaria de una actividad a caballo entre dos países, dos culturas y dos escenarios periodísticos diversos. Ofrecen la versión hispano mexicana de las redes intelectuales trasatlánticas que se establecieron entre España y América en torno al hispanoamericanismo, primero, y la hispanidad, después. Y su importancia en este sentido no puede menoscabarse, sino que más bien obliga a profundizar en los lazos que estos escritores y periodistas entablaron con sus contemporáneos y sus influencias recíprocas. 


\section{Bibliografía}

ALCÁZAR, Ricardo de (Florisel) (1922): Por el alma y el habla de Castilla, Prólogo de Felipe Sassone, México, "El día español".

----- (1927): El cuento y la cuenta del oro de América, México, Imprenta de Manuel León Sánchez.

----- (1928): El cetro, las cruces y el caduceo (en busca de la conciencia de la colonia), México, Imprenta de Manuel León Sánchez.

(1928): Unión, fusión y confusión de la colonia (un esquema de superestructura racional), México, Imprenta de Manuel León Sánchez.

----- (1934): El gachupín. Problema máximo de México, México, El Ideal.

----- (1944): Cómo hablamos en México (Sintaxis sin tasa oral y escrita cogida al vuelo). México, Costa-Amic.

BADA, Juan A. (1951): Ricardo de Alcázar (Florisel). Bosquejo biográfico y crítico. México, s.p.i.

BADÍA MALAGRIDA, C. (1920): Ideario de la colonia española. Su organización y su programa. México: Talleres Tipográficos Don Quijote.

BAILY, S. (1999): Immigrants in the lands of promise. Italians in Buenos aires and New York City, 1870-1914, Ithaca, Cornell University Press.

BLANCO, J.A., DACOSTA, A. (coords.) (2014): El asociacionismo de la inmigración española en el exterior. Significación y vinculaciones, Madrid, Silex.

CÍRCULO VASCO ESPAÑOL (1935): La querella de los vascos en México. Documentos en probanza sin comentarios. México, s.p.i.

DALLA CORTE, G., PRADO, G.H. (2006): "Luces y sombras de dos paradigmas del americanismo español en la renovación del diálogo hispanoamericano (19021912)", en Anuario de Estudios Americanos, vol. 63, núm. 2, pp. 195-216.

DE HOYOS PUENTE, J. (2012): “Catolicismo, laicismo y nación de las Españas en México: gachupines frente a refugiados", en SUÁREZ CORTINA, M., TREJO ESTRADA, E., CANO ANDALUZ, A. (coords.): Cuestión religiosa. España y México en la época liberal, Santander, Ediciones de la Universidad de Cantabria, Universidad Nacional Autónoma de México, pp. 393-428. 
(2011): "Patriotas en el exilio: Estado y Nación en el pensamiento político en torno a la revista "Las España" y la agrupación europeísta de México", en MATEOS LÓPEZ, A., SÁNCHEZ ANDRÉS, A. (coords.): Ruptura y transición: España y México, 1939, Madrid, Eneida, pp. 117-136.

DE MARÍA y CAMPOS, A. (1960), Reseña histórica del periodismo español en México, 1821-1932, México, Cía. Editora, Distribuidora de Ediciones, S.A.

DEVOTO, F. (2003a)), “Ideas políticas y prácticas migratorias argentinas en una perspectiva de largo plazo (1852-1950)", en SÁNCHEZ ALBORNOZ, N., LLORDÉN MIÑNAMBES, M. (Coords.): Migraciones iberoamericanas. Reflexiones sobre economía, política y sociedad, Asturias, Fundación Archivo de Indianos, pp. 173220.

DEVOTO, F. (2004): Historia de la inmigración en la Argentina, Buenos Aires, Editorial Sudamericana.

DUARTE, A. (1998): La República del emigrante. La cultura política de los españoles en la Argentina (1875-1910), Lleida, Milenio.

FIGUEROA ESQUER, R. (1998): “El Correo español: la prensa españolista mexicana y el 98", en Cuadernos Hispanoamericanos, núm. 557-558, pp. 87-98.

FERNÁNDEZ CUÉ, B. (1917): Los españoles y el nacionalismo mexicano. Interesante conferencia dada por Baltasar Fernández Cué en el salón Ibacheta, de Pachuca, y en el museo arqueológico de la capital el 25 y 28 de septiembre próximo pasado. Obsequio de "Iberia", revista mensual española a sus lectores. México, Tipografía y litografía "La Carpeta".

FERNÁNDEZ VICENTE, M.J. (2005): “El Estado español y la emigración, 1880-1985", en ESCRIVÁ, Á., BERMÚDEZ, A., MORAES, N. (eds.), Migración y participación política, Madrid, Consejo Superior de Investigaciones Científicas, pp. 265-295.

GARABEDIAN, M. (coord.) (2017): La prensa periódica española en América Latina. Voces, prácticas y diálogos para la identidad española en la diáspora, Buenos Aires, Leviátán.

GARCÍA SEBASTIANI, M. (2005): "La eficacia de las redes y los resultados de los vínculos: las élites de los inmigrantes españoles en la Argentina (1862-1923)", en Revista Complutense de Historia de América, vol. 31, pp. 147-176.

GARCÍA-SEDAS, P. (2009): Humberto Rivas Panedas. El gallo viene en aeroplano. Poemas y cartas mexicanas, Madrid, Renacimiento. 
GIL LÁZARO, A. (2006): “¿Hidalgo o gachupín? Imágenes en torno al inmigrante español en el México revolucionario", en SÁNCHEZ, A., PÉREZ, T., LANDAVAZO, M.A. (coords.): Imágenes e imaginarios sobre España en México, siglos XIX y XX, Morelia, Porrúa, pp. 367-399.

----- (2015): Inmigración y retorno. Españoles en la ciudad de México, 1900-1936, Madrid, Marcial Pons, Instituto de Estudios Latinoamericanos, Universidad de Alcalá.

----- (2015): “El asistencialismo en la inmigración española a México. El modelo de las Sociedades de Beneficencia, S. XIX y XX", en Estudios Migratorios Latinoamericanos, núms. 78-79, pp. 79-104.

LANZAGORTA UNAMUNO, E. (1949): Hispanidad en México, Bilbao, Vizcaína.

LIDA, C.E (2006): "Españoles inmigrantes y exiliados: el caso de México", en Varios Autores, De la España que emigra a la España que acoge, Madrid, Fundación Francisco Largo Caballero, pp. 121-131.

------ (1997): Inmigración y exilio. Reflexiones sobre el caso español, México, Siglo XXI Editores, El Colegio de México.

MAC GREGOR, J. (2002): Revolución y diplomacia: México y España, 1913-1917, México, Instituto Nacional de Estudios Históricos de la Revolución Mexicana.

MALUQUER DE MOTES, J. (2007): "La incidencia de la Gran Depresión y de la Guerra Civil en la población de España (1931-1940)", en Revista de Demografía Histórica, XXV/II, segunda época, pp. 131-166.

MARCOS, D. (1915a): México y los españoles. México, s.p.i.

----- (1915b): Acaparadores y amoladores. México, s.e.

----- (1924): Liga española de defensa y protección en México. Unirse es triunfar. México: Imprenta de Manuel León Sánchez.

------ (1926): España México (guía de emigrantes), México, s.p.i.

----- (1929): iGood-bye Spain! Adiós España!, México, Imprenta Azteca.

MEYER, L. (2001): El cáctus y el olivo. Las relaciones de México y España en el siglo XX. Una apuesta equivocada, México, Océano. 
MIQUEL, A. (2008): "Presentación", en MORA, P., MIQUEL, Á. Españoles en el periodismo mexicano, siglos XIX y XX, México, Universidad Nacional Autónoma de México, Universidad Autónoma del Estado de México, pp. 193-196.

MORA, P., MIQUEL, Á. (Compilación, textos y notas) (2006): Barco en tierra. España en México, México: Universidad Nacional Autónoma de México, Dirección General de la Divulgación de la Ciencia, Fundación Pablo Iglesias.

----- (2008): Españoles en el periodismo mexicano, siglos XIX y XX, México, Universidad Nacional Autónoma de México, Universidad Autónoma del Estado de México.

MORA, P., (2008): "Telesforo García: articulista y polemista en El Centinela", MORA, P., MIQUEL, Á. (compilación y edición): Españoles en el periodismo mexicano, siglos XIX y XX. México: Universidad Nacional Autónoma de México, Universidad Autónoma del Estado de México, pp. 123-136.

MOYA, J.C. (2004): Primos y extranjeros. La inmigración española en Buenos Aires, 1850-1930, Buenos Aires, Emecé.

NIÑO RODRÍGUEZ, A. (1993): “Hispanoamericanismo, regeneración y defensa del prestigio nacional (1898-1931)", en PÉREZ HERRERO, P., TABANERA, N. (coords.): España e Iberoamérica: un siglo de políticas culturales, Madrid, Asociación de Investigación y Especialización sobre Temas Iberoamericanos (AIETI), pp. 15-48.

NÚÑEZ SEIXAS, X.M. (2003): “Liderazgo étnico en comunidades de emigrantes: algunas reflexiones”, en SÁNCHEZ ALBORNOZ, N., LLORDÉN MIÑAMBRES, M. (Coords.): Migraciones iberoamericanas. Reflexiones sobre economía, política y sociedad, Asturias, Fundación Archivo de Indianos, pp. 347-388.

ORTS RAMOS, A. (1918): Elogio sentimental de la emigración española en América, México, Compañía Impresora Mexicana.

PÉREZ VEJO, T. (2010): "La difícil herencia: hispanofobia e hispanofilia en el proceso de construcción nacional mexicano", en SUÁREZ CORTINA, M. y PÉREZ VEJO, T. (coords.): Los caminos de la ciudadanía. México y España en perspectiva comparada, Santander, PubliCan y Universidad de Cantabria, pp. 219-230.

----- (2009): "La extranjería en la construcción nacional mexicana", en YANKELEVICH, P.: Nación y extranjería. La exclusión racial en las políticas migratorias de Argentina, Brasil, Cuba y México, México, Universidad Nacional Autónoma de México, pp. 147-185. 
PÉREZ MONTFORT, R. (1993): Hispanismo y falange. Los sueños imperiales de la derecha española en México, México, Fondo de Cultura Económica.

RUEDA HERRANZ, G. (2008): “¿Cómo se integraron en los países americanos los emigrantes españoles?", en BLANCO RODRÍGUEZ, J.A. (coord.): El asociacionismo en la emigración española a América, Salamanca, Universidad Nacional de Educación a Distancia, Junta de Castilla y León, pp. 31-50.

MOYA, J.C. (2008): "Los inmigrantes y sus asociaciones: una perspectiva histórica y global", en Apuntes de investigación del CECYP, núm. 13, pp. 10-50.

SÁNCHEZ-ALBORNOZ, N. (coord.) (1988): Españoles hacia América: la emigración en masa, 1880-1930, Madrid, Alianza Editorial.

SÁNCHEZ ANDRÉS, A., PÉREZ HERRERO, P. (2015): Historia de las relaciones entre España y México, 1821-2014, Madrid, Marcial Pons, Universidad de Alcalá.

SEPÚlVEDA, I. (2005): El sueño de la Madre Patria. Hispanoamericanismo y nacionalismo, Madrid, Marcial Pons.

SERNA, A.M. (2014): "Prensa y sociedad en las décadas revolucionarias, 1910-1940", en Secuencia, núm. 86, pp. 111-149.

STEWARD, L.N. (1965): "Spanish Journalism in Mexico, 1867-1879", en The Hispanic American Historical Review, vol. 45, núm. 3, pp. 422-433.

TABANERA, N. (1996): Ilusiones y desencuentros: la acción diplomática republicana en Hispanoamérica (1931-1939), Madrid, Fundación Centro Español de Estudios de América Latina.

TORRICELLI, V. (2017): Somos lo que vamos siendo. Identidades ítaloargentinas en el Buenos Aires del siglo XXI, Madrid, Marcial Pons, Instituto de Estudios Latinoamericanos.

TOUSSAINT, F. (1989): Escenario de la prensa en el porfiriato, Colima, Universidad de Colima, Fundación Manuel Buendía.

URÍAS HORCASITAS, B. (2010): “Una pasión antirrevolucionaria. El conservadurismo hispanófilo mexicano (1920-1960)", en Revista Mexicana de Sociología, año 72, núm. 4, pp. 599-628.

VALDÉS FERNÁNDEZ, M. (Conde de Fox) (1918): Impresiones de México, Prólogo del general Francisco J. Múgica, México, Talleres Tipográficos. 
VIEYRA SÁNCHEZ, L. (2008): “Adolfo Llanos y Alcaraz: entre la polémica y el nacionalismo", en MORA, P., MIQUEL, Á. (compilación y edición): Españoles en el periodismo mexicano, siglos XIX y XX. México: Universidad Nacional Autónoma de México, Universidad Autónoma del Estado de México, pp. 91106.

VILLAGRÁN, A. (1942): “El inmigrante español”, editado por la Revista Población. México, tercera edición.

YANKELEVICH, P. (2004): "Nación y extranjería en el México revolucionario", en Cuicuilco, vol. 11, núm. 31, pp. 135-156.

ZULOAGA, M. (1996): "La diplomacia española en la época de Carranza: Iberoamericanismo e Hispanoamericanismo, 1916-1920", en Historia Mexicana, vol. XLV, núm. 4, pp. 807-842. 